tuỷ xương chiếm $67.85 \%, 64.28 \%$. Trong khi đó ở giai đoạn sớm của bệnh, các hình ảnh tổn thương ổ cối, xẹp chỏm xương đùi không thấy xuất hiện thì trên hình ảnh chụp $\mathrm{CHT}$ giai đoạn muộn, các dấu hiệu này đã xuất hiện với tỷ lệ trên, điều này có thể thấy rằng ở giai đoạn muộn của bệnh, mức độ tổn thương đã lan rộng, chỏm xương đùi bị biến dang nhiều kéo theo các tổn thương khác như tràn dịch, hẹp khe khớp, tổn thương ổ cối.

\section{KẾT LUÂ̂N}

- Kết qủa chúng tôi chỉ ra rằng nhóm tuổi 3159 mắc HTVKCXĐ chiếm tỷ lệ lớn nhất $70.0 \%$ và tỷ lệ bệnh nhân nam giới mắc với tỷ lệ cao $86.67 \%$. Tỷ lệ phát hiện HTVK trên phim Xquang chỉ đạt $65.45 \%$ trong số bệnh nhân đã được chẩn đoán HTVK. Có $76.67 \%$ bị tổn thương hai bên chỏm xương đùi.

- Hình ảnh ổ đặc xương kèm khuyết xương $83.33 \%$, xẹp chỏm xương đùi $69.44 \%$ và hình ảnh đặc xương $27.77 \%$ được quan sát thấy trên phim Xquang.

- Hình ảnh phù tuỷ xương trên xung T2-Pd với $66.98 \%$ và tràn dịch khớp háng chiếm $68.86 \%$ chỏm xương đùi, xẹp chỏm xương đùi chiếm $59.43 \%$, và gãy xương dưới sụn chiếm $52.83 \%$ được quan sát thấy trên phim CHT. Giai đoạn sớm cho thấy hình ảnh dải giảm tín hiệu trên $\mathrm{T} 1$ chiếm $81.81 \%$, hình ảnh phù xương trển xung T2-Pd chiếm $77.27 \%$, hình ảnh đường đôi trên T2-Pd và hình ảnh tràn dịch khớp háng chiếm $72.72 \%$. Giai đoạn muộn cho thấy hình ảnh xẹp chỏm chiếm $75.0 \%$, phù tủy xương và tràn dịch khớp háng $67.85 \%$ và $64.28 \%$.

\section{TÀI LIÊU THAM KHẢO}

1. Lưu Thị Bình (2011). Hình ảnh hoại tử vô khuẩn chỏm xương đưi ở người lớn giai đoạn sớm trên phim chup x-quang, cộng hưởng từ. Tạp chí khoa học và cồng nghệ. 89, 89-95.

2. Lưu Thi Bình, Đoàn Văn Đê, Pham Minh Thông (2009). Xác định hình ảnh tổn thương chỏm xương đưi trên phim xquang, cộng hưởng từ trong hoại tử vô mạch chóm xương đưi ở ngườ lớn. Tạp chí nội khoa, 125.

3. Gardeniers JWM (1993). Report of the Committee of Staging and Nomenclature. ARCO News Letter. 5 (2), 79-82.

4. Lưư Thị Bình (2011). Nghiên cứu lâm sàng và chẩn đoán hình ảnh hoại tứ vô khuẩn chỏm xương đùi ở người lớn. Luận án tiến sĩ y học - Trường Đai học y dược Thái Niguyên. 1-135.

5. Lể Vằn Phước (2012). Cộng hưởng từ cơ bản. NXB Y học. 177-183.

6. Cao Thiền Tượng (2015). Vai trò của MRI trong chẩn đoán hoại tự vô khuân chỏm xương đùi. Tạp chí Y hoc thức hành.

7. Li S., Liao R., Li Y., (2010). Diaanosis of MRI on the Early Avascular Necrosis of Femoral Head. Journal of Traditional Chinese Medicine University of Huna. 2010-04.

8. Bassett, L., et al.: MRI in the Early Diaqnosis of Ischemic Necrosis of the Femoral Head. Clin. Ortho.214:237-248.

9. Beltran, J., et al.: Femoral Head AVN: MR Imaqina with Clinical-Patholoqical and Radionucide Correlation. Radiology; 166:215-220.

\title{
MỐI LIÊN QUAN GIỮA THANG ĐIỂM IHC4 VÀ TÍP PHÂN TỬ CỦA UNG THƯ VÚ CÓ THỤ THỂ NộI TIẾT DƯƠNG TÍNH GIAI ĐOẠN I-II
}

\section{TÓM TẮT}

Phân tâng nguy cơ và phân typ phân tử ở bệnh nhân UTV giai đoạn sớm rất quan trọng, để đưa ra liệu pháp điều trị bổ trợ phù hợp, tránh điều trị quá mức hoăcc dưới mức cho bệnh nhân. Mục tiêu: Đánh giá mối liên quan giữa các nhóm nguy cỡ IHC4 với typ phân tử ung thư vú có thụ thể nội tiết giai đoạn I-II. Đối tượng và phương pháp nghiên cứu: 226 bệnh nhân ung thư vú được phân tâng nguy cơ theo IHC4 và phân typ phân tử bằng nhuộm $H M M D$ với $E R, P R$,

\section{*Bênh viên $K$}

Chịu trách nhiệm chính: Nguyễn Văn Chủ

Email: chunv@bvk.org.vn

Ngày nhận bài: 6.01.2021

Ngày phản biện khoa học: 25.2.2021

Ngày duyệt bài: 5.3.2021

\section{Nguyễn Văn Chủ*, Chu Thị Trang*}

Her2/neu, Ki67 và đánh giá mối liên quan. Kết quả nghiên cứu: nhóm nguy cơ thấp hay gặp ở nhóm lòng ống $A$ nhất (chiếm 73,7\%). Trái lại, nhóm lòng ống B HER2+có tỉ lệ cao nhất $(38,0 \%)$ ở IHC4 cao. Kểt luận: Nhóm ngư cơ thấp chiếm tỷ lệ cao nhất ở typ lòng ống $A$, trái lại nhóm nguy cơ cao chủ yếu gặp ở typ lòng ống $B$ HER2+.

Tư khóa: Ung thư vú, Phân tâng nguy cơ, Typ phân tứ, Hóa mô miến dịch.

\section{SUMMARY}

RELATIONSHIP BETWEEN IHC4 SCORE AND MOLECULAR SUBTYPE OF POSITIVE HORMON RECEPTOR BREAST CANCER WITH STAGE I-II

Risk stratification and molecular subgroup in BC patients with early stage is very important, in order to provide appropriate adjuvant therapy, to avoid over or 
under treatment for the patient. Purpose: Evaluation of the association between IHC4 risk groups and the molecular type of positive HR breast cancer with stage I-II. Methods: 226 breast cancer patients were classified in risk and molecular subgroup by IHC stain and evaluating their relations. Results: The low-risk group was the most common in the subgroup luminal A (accounting for $73.7 \%$ ). In contrast, subtype luminal B HER2 + had the highest proportion $(38.0 \%)$ in the high IHC4. Conclusion: The low-risk group had the highest proportion in the subgroup luminal $A$, whereas the high-risk group was mainly found in the subtype luminal B HER2 +.

Key words: Breast cancer, Risk stratification, Molecular subgroup, IHC.

\section{I. ĐĂT VẤN ĐỀ}

Ung thư vú là một bệnh không đồng nhất. Các khối u vú với hình ảnh mô bệnh học $(\mathrm{MBH})$ tương tự nhau có thể biểu hiên lâm sàng, mức độ ác tính và đáp ứng với điều trị trái ngược nhau. Sự phân tích khía cạnh bộc lộ gen và các đặc trưng hóa mô miễn dịch (HMMD) cho rằng ung thư vú không phải là một thực thể đơn thuần mà là một bệnh không đồng nhất, gồm một số typ phân tử đã được nhận ra. Phác đồ điểu trị ung thư vú (UTV) giai đoạn sớm I, II có thụ thể nội tiết dương tính gồm liệu pháp nội tiết, cân nhắc sử dụng hóa chất với những trường hợp nguy cơ tái phát cao hoặc typ phân tử có tiên lượng xấu. Do vậy, việc phân tầng nguy cơ ở những bệnh nhân này rất quan trong, để đưa ra liệu pháp điều trị phù hợp, tránh điều trị quá mức cho bệnh nhân. Trong những xét nghiệm phân tầng nguy cơ bệnh nhân, Oncotype DX có giá trị cao nhất và được đưa vào phân loại AJCC lần thứ 8 [1]. Tuy nhiên, những xét nghiệm này đòi hỏi chi phí và công nghệ cao, nên chưa đước áp dụng phổ biến ở các nước đang phát triển. Do vậy năm 2011, Cuzick và cs [2] đã thiết lập thang điểm IHC4 (Immunohistochemistry 4) được tính toán dựa trên 4 dấu ấn $E R, P R, H E R-2$ và Ki67, với cách tính toán đơn giản và chi phí thấp, nhằm tiên lượng thời gian tái phát của bênh nhân UTV giai đoạn sớm có thụ thể nội tiết dương tính. Nghiên cứu cũng chỉ ra rằng thang điểm IHC4 có giá trị tiên lượng tương tự như thang điểm tái phát Oncotype Dx [2]. Ở Việt Nam rất ít nghiên cứu về vấn đề này. Vì vậy, chúng tôi thực hiện đề tài: Đánh giá mối liên quan giữa các nhóm nguy cơ IHC4 với typ phân tử ung thư vú có thụ thế nội tiết giai đoạn I-II.

II. ĐỐl TƯỢNG VÀ PHƯƠNG PHÁP NGHIÊN CỨU

Đối tượng nghiên cứu. Gồm 226 bệnh nhân ung thư vú được phẫu thuật tại Bệnh viện
K, từ năm 2017 đến năm 2019.

Tiêu chuẩn chọn bệnh nhân

- UTV nguyên phát giai đoạn I-II với chẩn đoán $\mathrm{MBH}$ là UTBM xâm nhâp, nhuộm hóa mô miễn dịch (HMMD) dương tính với thụ thể nội tiết.

- Có tiêu bản nhuộm $\mathrm{HE}$ và khối nến chứa bệnh phẩm đủ để nghiên cứu.

- Chưa được điều trị hóa chất và/hoặc xạ trị trước mổ.

Tiêu chuẩn loại trừ: Bệnh nhân không thỏa mãn các tiêu chuẩn trên

- UTV tại chỗ, tái phát hoặc ung thư từ nơi khác di căn tới vú.

- UTV ở nam giới.

Phương pháp nghiên cứu

Thiết kế nghiên cứu: Nghiên cứu mô tả cắt ngang.

Các bước tiến hành nghiên cứu

Nghiên cứu mô bệnh học: Chẩn đoán typ mô bệnh học (MBH).

Nghiên cứu HMMD: Các mẫu mô được nhuộm HMMD bằng máy với các dấu ấn: $E R, P R$, Her-2/neu và Ki67. Đánh giá kết quả HMMD theo các hướng dẫn quốc tế.

Phân tầng mức độ nguy cơ: thấp, trung bình và cao theo thang điểm IHC4:

$\mathrm{IHC} 4=94,7 \times\left[-0,1 \mathrm{ER}_{10}-0,079 \mathrm{PR}_{10}+\right.$ $0,586 \mathrm{HER} 2+0,240 \times \ln (1+10 \times \mathrm{Ki} 67)]$

Địa điểm nghiên cứu: Nghiên cứu này được thực hiện tại khoa Giải phẩu bệnh-tế bào, Bệnh viện $\mathrm{K}$.

Đạo đức trong nghiên cứu: Đề tài được hội đồng khoa học và đạo đức của Bệnh viện $\mathrm{K}$ phê duyệt.

Xử Iý số liệu: Xử lý số liệu trên phần mềm SPSS 20.0.

\section{KẾT QUẢ NGHIÊN CỨU}

Bảng 1. Tình trạng bộc lộ dâu ấn hóa mô miễn dich

\begin{tabular}{|c|c|c|c|}
\hline \multicolumn{2}{|c|}{ Dấu ấn HMMD } & Tân số (n) & Tỷ lệ (\%) \\
\hline $\begin{array}{c}\text { ER } \\
\text { (H- } \\
\text { score) }\end{array}$ & $1-99$ & 58 & 25,7 \\
\cline { 2 - 4 } & $100-199$ & 59 & 26,1 \\
\hline \multirow{4}{*}{ PR (\%) } & $\geq 200$ & 109 & 48,2 \\
\cline { 2 - 4 } & $<5$ & 31 & 13,7 \\
\cline { 2 - 4 } & $5-39$ & 52 & 23,0 \\
\cline { 2 - 4 } & $40-79$ & 57 & 25,2 \\
\hline \multirow{2}{*}{ Her-2 } & Dương tính & 86 & 38,1 \\
\cline { 2 - 4 } & Âm tính & 169 & 25,2 \\
\hline \multirow{2}{*}{$\begin{array}{c}\text { Ki67 } \\
\text { (\%) }\end{array}$} & $<10$ & 11 & 74,8 \\
\cline { 2 - 4 } & $10-19$ & 36 & 4,9 \\
\cline { 2 - 4 } & $\geq 20$ & 179 & 79,2 \\
\hline \multicolumn{2}{|c|}{ Tống } & $\mathbf{2 2 6}$ & $\mathbf{1 0 0 , 0}$ \\
\hline
\end{tabular}


Nhận xét: $E R \quad 200$ điểm hay gặp nhất (chiếm 48,2\%), hai nhóm còn lại chiếm tỉ lệ lần lượt là $25,7 \%$ và $26,1 \%$. $P R(+) \geq 80 \%$ chiếm tỉ lệ cao nhất là 38,1 . Tî lệ HER-2 dương tính chiếm $25,2 \%$. Ki67 dương tính $\geq 20 \%$ hay gặp nhất (chiếm 79,2\%).

Bảng 2. Phân tâng nguy cơ ung thư vú giai đoan I-II theo IHC4

\begin{tabular}{|c|c|c|}
\hline Phân tầng nguy cơ & $\mathbf{N}$ & $\mathbf{\%}$ \\
\hline Thấp & 19 & 8,4 \\
\hline Trung bình & 86 & 38,1 \\
\hline Cao & 121 & 53,5 \\
\hline Tống & $\mathbf{2 2 6}$ & $\mathbf{1 0 0 , 0}$ \\
\hline
\end{tabular}

Nhận xét: Điểm IHC4 từ -68,29 đến 185,72 (giá trị trung bình là 41,04, giá trị trung vị là 34,26; độ lệch chuẩn là 53,22). Nhóm UTV nguy cơ cao chiếm tỷ lệ cao nhất là $53,5 \%$, tiếp theo là nhóm có nguy cơ trung bình chiếm $38,1 \%$, cuối cùng là UTV nguy cơ thấp là $8,4 \%$.

\section{Bảng 3. Tỉ lê típ phân tử}

\begin{tabular}{|c|c|c|c|}
\hline \multicolumn{2}{|c|}{ Típ phân tử } & Tần số (n) & Tỷ lệ (\%) \\
\hline \multicolumn{2}{|c|}{ Lòng ống A } & 59 & 26,1 \\
\hline \multirow{2}{*}{ Lòng } & HER-2 (-) & 110 & 48,7 \\
\cline { 2 - 4 } ông BER-2 (+) & 57 & 25,2 \\
\hline \multicolumn{2}{|c|}{ Tống } & $\mathbf{2 2 6}$ & $\mathbf{1 0 0 , 0}$ \\
\hline
\end{tabular}

Nhận xét: Trong 226 bệnh nhân UTV có thụ thể nội tiết dương tính giai đoạn I, II được chia thành 3 dưới nhóm phân tử, nhóm lòng ống $B$ HER-2 (-) chiếm tỉ lệ cao nhất $(48,7 \%)$, tiếp theo là nhóm lòng ống $A$ (chiếm $26,1 \%$ ), cuối cùng là nhóm lòng ống B, HER-2 (+) ( chiếm 25,2\%).

Bảng 4. Mối liên quan thang điếm IHC4 theo típ phân tứ

\begin{tabular}{|c|c|c|c|c|}
\hline \multirow{3}{*}{$\begin{array}{l}\text { Nhóm } \\
\text { nguy co }\end{array}$} & \multicolumn{3}{|c|}{ Típ phân tử } & \multirow{3}{*}{ Tổng } \\
\hline & $\begin{array}{c}\text { Lòng } \\
\text { ống A }\end{array}$ & $\begin{array}{c}\text { Lòng } \\
\text { óng B, } \\
\text { HER2 (-) }\end{array}$ & $\begin{array}{c}\text { Lòng } \\
\text { ống } B \text {, } \\
\text { HER2 } \\
(+)\end{array}$ & \\
\hline & \multicolumn{3}{|c|}{ n (\%) } & \\
\hline Thấp & $14(73,7)$ & $5(26,3)$ & $0(0,0)$ & $19(8,4)$ \\
\hline $\begin{array}{l}\text { Trung } \\
\text { binh }\end{array}$ & $\begin{array}{c}35 \\
(40,7)\end{array}$ & $\begin{array}{c}40 \\
(46,5)\end{array}$ & $\begin{array}{c}11 \\
(12,8)\end{array}$ & $\begin{array}{c}86 \\
(38,1) \\
\end{array}$ \\
\hline Cao & $10(8,3)$ & $65(53,7)$ & $46(38,0)$ & $121(53,5)$ \\
\hline
\end{tabular}

Tống $59(26,1)$ 110(48,7) 57(25,2) 226(100)

Nhân xét: Trong 3 nhóm phân típ phân tử của mẩu nghiên cứu của chúng tôi, nhóm giá trị IHC4 thấp hay gặp ở nhóm lòng ống $A$ nhất (chiếm $73,7 \%$ ), tiếp theo là nhóm lòng ống $B$, HER2 (-) (chiếm 26,3), lòng ống $B$, HER2 (+) không có trường hợp nào. Tỉ lệ nhóm lòng ống $A$ trong các giá trị IHC4 từ thấp tới cao giảm dần, thấp nhất ở nhóm giá trị IHC4 cao (chiếm $8,3 \%$ ). Nhóm giá trị IHC4 cao có tỉ lệ nhóm lòng ống B, HER-2 (-) cao nhất (chiếm 53,7\%), sau đó là nhóm lòng ống $B$, HER-2 (+) (chiếm $38,0 \%$ ), cuối cùng là nhóm lòng ống $A$ (chiếm $8,3 \%)$. Và sự khác biệt giữa nhóm giá trị tiên lượng IHC4 và dưới típ phân tử có ý nghĩa thống kê với $p=0,000<0,001$.

\section{BÀN LUÂN}

Sự bộc lộ hóa mô miễn dịch trong ung thư vú: Bảng 1 cho thây thụ thể Estrogen (ER) là dấu ấn quan trọng trong chẩn đoán, tiên lượng ung thư vú xâm nhâp. Mô u dương tính nhân với ER ít nhất $1 \%$ ở bất kì cường độ nào đều nhận được lợi ích từ việc điều trị theo liệu pháp hoocmôn. Theo ASCO/CAP năm 2010, đưa ra guidline hướng dẫn chẩn đoán ER dương tính khi tế bào u bộc lộ $E R \geq 1 \%$. Tuy nhiên có nghiên cứu cho rằng tỉ lệ u dương tính với $E R \quad 1-5 \%$, không có hiệu quả lâm sàng khi điều trị bằng liệu pháp nội tiết. Nhưng bản cập nhật 2019 vẫn duy trì ngưỡng chẩn đoán ER dương tính là ít nhất $1 \%$ tế bào u dương tính yếu, tuy nhiên nếu dương tính $1-10 \%$ nên ghi chú là dương tính yếu. Thụ thể progesterone (PR) cũng lên với nhân tế bào, được biết đến là gen điều hòa ER- bộc lộ $2 / 3$ trường hợp ER dương tính. Tuy nhiên, cho tới nay chỉ có ER được chứng minh là yếu tố có giá trị dự đoán lợi ích từ việc sử dụng Tamoxifen, đồng thời PR không có vai trò trong đánh giá hiệu quả chọn lọc của ức chế aromatase (AI). Nghiên cứu $B$ Yeo và cộng sứ (2015) [3], trên 124 bệnh nhân UTV có thụ thể nội tiết ER dương tính ở giai đoạn sớm cho kết quả ER (theo Hscore) 100-199 chiếm tỉ lệ cao nhất (51\%), $\geq 200$ chiếm $47 \%$, cao hớn nghiên cứu của chúng tôi. Tỉ lệ \% PR trong nghiên cứu này có giá trị $\geq 80 \%$ chiếm $53 \%$, cao hơn nghiên cứu của chúng tôi (chiếm 38,1\%). Ngược lại, giá trị Ki67 trong nghiên cứu của chúng tôi cao hơn với giá trị $\geq 20 \%$ chiếm $79,2 \%$ so với $41 \%$ trong nghiên cứu của $B$ Yeo. Sự khác biệt này có thể do nghiên cứu của $B$ Yeo những bệnh nhân HER2 dương tính bị loại bỏ khỏi nghiên cứu. Nhiều nghiên cứu phân tích tổng hợp chỉ ra giá trị tiên lượng độc lập của Ki67 ở những bệnh nhân ER dương tính, hạch âm tính. Một nghiên cứu của Viện Ung thư Châu Âu cho thấy giá trị Ki67 cao ( $\geq 32 \%$ ) dự đoán lợi ích từ liệu pháp điều trị hóa chất bổ trợ ở 1241 bệnh nhân típ lòng ống, có di căn 1-3 hạch. Bên cạnh đó, Ki67 cũng có giá trị tiên lượng đáp ứng hoàn toàn trên mô bệnh học (pCR) trong nhiều nghiên cứu, bệnh nhân có chỉ số Ki67 cao thì có tỉ lệ tái phát, tử vong cao hơn so với nhóm chỉ số Ki67 trung bình và thấp. HER-2 là dấu ấn nằm trong nhóm các thụ thể 
yếu tố tăng trưởng gồm EGFR (HER1), ERBB3 (HER3) và ERBB4 (HER4)- điêuu hòa sự tăng sinh, phát triển và sống sót của các tể bào bình thường. HER2 nằm ở trên bề măt của tế bào bình thường, thường ở mức độ yếu. Tuy nhiên khi có khuếch đại thì bộc lộ quá mức ở bề mặt tế bào u trong khoảng 10-20\% UTV, thường liên quan đến bệnh tiến triển nhanh hơn, tỉ lệ tái phát cao hơn và thời gian sống ngắn, do đó làm tăng sinh tế bào u và tăng sinh mạch máu. Điều trị đầu tay vẫn là liệu pháp điều trị đích kháng HER2-Trastuzumab (herceptin). Trên thực hành lâm sàng, kiểm tra sự khuếch đại HER2 luôn được yêu câu với những trường hợp chẩn đoán UTV lần đầu tiên. Sư khuếch đại của protein HER2 có thể đánh giá bằng HMMD hoăc lai tại chỗ. Do HMMD có sắn, chi phí thấp, phổ biến ở hầu hết các trung tâm nên HMMD là phương pháp sử dụng đầu tay, với trường hợp HER2 dương tính $2+$ nên đánh giá sự khuếch đại của gen. Ở nghiên cứu của chúng tôi, sử dụng cả hai phương pháp HMMD và FISH cho kết quả có 25,2\% UTV dương tính với HER-2. Tỷ lệ này tương đương với nghiên cứu của Maoli Wang, Hui Hu [4].

Phân tâng nguy cơ theo IHC4: Ở những bênh nhân giai đoạn sớm I, II việc điều trị hóa chất bổ sung sau phẫu thuât bên canh điều trị liệu pháp nội tiết còn nhiều tranh cãi, do vậy việc phân tầng nguy cơ để điều trị cá thể hóa thích hợp ngày càng quan trọng, tránh điều trị quá mức và điều trị dưới mức. Năm 2011, Cuzick và cs [2] đã thiết lập thang điểm IHC4 được tính toán dựa trên 4 dấu ấn HMMD là $E R, P R, H E R-2$ và Ki67, với cách tính toán đơn giản và chi phí thấp, nhằm tiên lượng thời gian tái phát của bệnh nhân. Nghiên cứu đồng thời cũng chỉ ra rằng các tín hiệu đa gen khác và tiên lượng trong ung thư vú đáp ứng với hóa trị liệu bồ trợ mới, cũng đã được kiểm tra bởi các nghiên cứu khác. Trong nghiên cứu của chúng tôi (bảng 2), nhóm có giá trị tiên lượng IHC4 dao động từ 68,29 đên 185,72 (giá trị trung bình là 41,04; độ lệch chuẩn là 53,22 ) nhóm giá trị IHC4 cao chiếm tỉ lệ cao nhất là 53,5\% với 121 trường hợp, tiếp theo là nhóm có giá trị tiên lượng trung bình chiếm $38,1 \%$, cuối cùng là nhóm có giá trị tiên lượng thấp chiếm $8,4 \%$. So với nghiên cứu của Abubakar và cs [5] thấy giá trị IHC4 trung

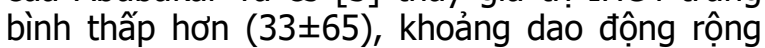
hơn (-148 tới 289), sự chênh lệch này có thể do mẫu nghiên cứu của nhóm tác giả này chọn lớn hơn (316 bệnh nhân có ER dương hoặc và PR dương tính). Nghiên cứu khác của Bakre va cs
[6] trên 543 bệnh nhân giá trị IHC4 chia thành 3 nhóm nguy cơ thấp chiếm $42,0 \%$, nguy cơ trung bình chiếm $33,0 \%$, cuối cùng là nhóm nguy cơ cao chiếm $25 \%$. Nghiên cứu cũng chỉ ra rằng nhóm nguy cơ thấp $(n=226)$ có thời gian sống không di căn xa (DMFS: $96 \%$ ) cao hơn so với nhóm nguy cơ trung bình ( $n=179)$ (DMFS: $89 \%$, $\mathrm{p}=0,002)$ và nhóm nguy cơ cao $(\mathrm{n}=138)$ (DMFS: $91 \%, p=0,06$ ). Hai nhóm nguy cơ trung bình và cao có tỉ lệ tái phát xa sau 5 năm cao gấp $>2,4$ lần so với nhóm nguy cơ thấp.

Phân típ phân tử: UTBMVXN theo các típ phân tử đã trở thành một chẩn đoán bắt buộc trong tất cả các trường hợp do vai trò quan trọng trong việc điều trị và tiên lượng. Qua nhiều nghiên cứu phân tích gen và đối chiếu với giá trị HMMD, các nghiên cứu chỉ ra rằng dựa trên kết quả HMMD có thể phân típ các dưới nhóm phân tử, từ đó đem lại bảng phân loại có giá trị tiên lượng, giúp ích cho điều trị hơn. Các bảng phân loại về sau luôn có những thay đổi dựa trên các nghiên cứu lâm sàng về điều trị và theo dõi thời gian sống thêm. Típ lòng ống $A$ và lòng ống $B$ đều bôc lộ với thu thể hoóc-môn, được phân biêt dựa vào mức độ bộc lộ Ki67 và thụ thể nội tiết PR. Nghiên cứu của Goldhirsch và cộng sự cho thấy điểm cut-off của Ki67 là $14 \%$, con số này được đồng thuân trong hội nghi năm 2011. Năm 2013 cũng tại hội nghị này lần kế tiếp, các chuyên gia từ 94 quốc gia thống nhất lây cut-off của Ki-67 là 20\%. Giá tri PR cao đước cho là $\geq 20 \%$. Do việc điều trị và tiên lượng khác nhau giữa nhóm lòng ống $A$ và lòng ống $B$, nếu chỉ sử dụng $E R$, $P R$ để phân loại, một số bệnh nhân lòng ống $B$ sẽ phân loại nhầm sang nhóm lòng ống $A$, chính vì vậy sử dụng Ki-67 vào phân loại là cần thiết. Tuy nhiên, điểm cut-off Ki-67 vấn còn đang tiếp tục được nghiên cứu. Trong nghiên cứu của chúng tồi lây điểm cut-off của Ki-67 là $20 \%$, và $P R 20 \%$ để phân loai nhóm lòng ống $B$ có HER-2 âm tính với nhóm lòng ống A. Trong nghiên cứu của chúng tôi (bảng 3), 226 bênh nhân UTV giai đoạn sớm thây nhóm lòng ống $B, H E R-2(-)$ hay găp nhất chiếm $49,6 \%$; lòng ống $B, H E R-2$ và lòng ống $A$ chiếm tỉ lế ngang nhau (chiếm 25,2\%). Khi so sánh với nghiên cứu của các tác giả khác nhau cho thây tỉ lệ các típ phân tử có sự chênh lệch đáng kể. So sánh với nghiên cứu của $M$. C. De Santis và cs năm 2019 trên 681 bệnh nhân, típ lòng ống $A$ hay gặp nhất với tî lệ $79,9 \%$, cao hơn nghiên cứu của chúng tôi, nghiên cứu của Gnant và cộng sự cũng cho kết quả tương tự (nhóm lòng ống $A$ chiếm tî lệ cao 70,6\%) [7]. Nghiên cứu 
Abubakar và cộng sự trên những bênh nhân UTV giai đoạn sớm cho kết quả chênh lệch nhiều với nghiên cứu của chúng tôi, với tỉ lệ nhóm lòng ống $A$ chiếm 55,7\% [5]. Trong nghiên cứu của chúng tôi, áp dụng phân loai theo St Gallen 2013 với tiêu chuẩn chẩn đoán lòng ống $A$ ngoài $E R$ dương tính, HER-2 âm tính, còn dựa vào giá trị PR cao và chỉ số tăng sinh Ki67 thấp; muc đích để giảm thiểu tỉ lê bệnh nhân không được điều trị đúng. Tuy nhiên, điều này càng cần thêm những nghiên cứu với quy mô và tính chất chuyên sâu hơn nhằm tìm hiểu rõ hơn về bản chất phân típ phân tử phục vụ cho việc điều trị cho các bệnh nhân UTV hiệu quả hơn nữa.

Mối liên quan giữa IHC4 với phân típ phân tử: Theo kết quả nghiên cứu của chúng tôi (bảng 4), nhóm giá trị IHC4 thấp hay gặp nhóm lòng ống A nhất (chiếm $73,7 \%)$, tiếp theo là nhóm lòng ống $B$, HER2 (-) (chiếm 26,3), lòng ống $B$, HER2 (+) có 0 trường hợp (chiếm $0,0 \%$ ). Tỉ lệ nhóm lòng ống $\mathrm{A}$ trong các giá trị IHC4 tữ thấ tới cao giảm dần, thấp nhất ở nhóm giá trị IHC4 cao (chiếm $8,3 \%$ ), trong khi đó trong nhóm giá trị IHC4 cao thì nhóm lòng ống $B$ chiếm chủ yếu, cụ thể nhóm lòng ống $B, H E R 2(-)$ trong nhóm giá trị IHC4 cao thì cao hơn so với trong nhóm giá trị IHC4 thấp (lần lượt là $53,7 \%$ và $26,3 \%$ ). Sư khác biệt này có ý nghĩa thống kê với $p<0,001$. Một số nghiên cứu về phân típ phân tử và tỉ lệ tái phát tại chỗ của các bệnh nhân UTV cho kết quả dưới nhóm lòng ống $A$ tiên lượng tốt nhất với tỉ lệ di căn hach ít hơn, tỉ lê tái phát tại chỗ thấp 0,8-8\%. Hơn nữa, tî lệ bộc lộ dương tính với thụ thể nội tiết vừa là yếu tố tiên lượng tốt vừa có ý nghĩa dự báo đáp ứng với liệu pháp nội tiết. Dưới nhóm lòng ống $B$ có tiên lượng trung bình so với nhóm lòng ống $A$, nguy có tái phát tại chỗ là 1,5-8,7\%, cao nhất là trong 5 năm đâu sau khi chẩn đoán. Khuyến cáo điều trị hệ thống ở bệnh nhân UTV giai đoạn sớm năm 2013,115 với bệnh nhân lòng ống $A$, điều trị đầu tay là liệu pháp hoóc-môn, cân nhắc điều trị hóa chất độc tế bào ở một số bệnh nhân chon lọc thường <35 tuổi, gồm: thang điểm tái phát 21 gen cao, xét nghiệm 70 gen có nguy cơ cao, độ mô học III, di căn $\geq 4$ hach. Nghiên cứu của Cuzick và công sư (2011) đã chứng minh thang điểm IHC4 có thể cung cấp giá trị tiên lượng tương tự như thang điểm tái phát cho những bệnh nhân ER dương tính [2]. Do vâyy, thang điểm IHC4 góp phần bổ sung thêm giá trị tiên lượng thời gian tái phát, điêuu trị cho dưới nhóm phân tử, đặc biệt nhóm lòng ống $A$ ở giai đoạn I, II [8].

\section{KẾT LUÂN}

Qua nghiên cứu 226 bệnh nhân UTBM vú xâm nhập có thụ thể nội tiết dương tính, giai đoạn I-II bằng $\mathrm{HMMD}$, chúng tôi rút ra các kết luận sau:

- Sử dụng thang điểm IHC4 đã xác định được $53,5 \%$ là ung thư vú nhóm nguy cơ cao, tiếp đến là nhóm nguy cơ trung bình và $8,4 \%$ là nhóm nguy cơ thấp.

- Nhóm nguy cơ thấp chiếm tỷ lệ cao nhất ở typ lòng ống $A$, trái lại nhóm nguy cơ cao chủ yếu gặp ở typ lòng ống $B$ HER2+ $(p<0,05)$.

\section{TÀI LIẸU THAM KHẢO}

1. Sparano JA, Gray RJ, Makower DF, et al. Prospective Validation of a 21-Gene Expression Assay in Breast Cancer. N Engl J Med. 2015;373(21):2005-2014.

doi:10.1056/NEJMoa1510764

2. Cuzick J, Dowsett $M$, Pineda $S$, et al. Prognostic value of a combined estrogen receptor, progesterone receptor, Ki-67, and human epidermal growth factor receptor 2 immunohistochemical score and comparison with the Genomic Health recurrence score in early breast cancer. J Clin Oncol Off J Am Soc Clin Oncol. 2011;29(32):4273-4278. doi:10.1200/ JCO.2010.31.2835

3. Yeo B, Zabaglo L, Hills M, Dodson A, Smith $I_{\text {, }}$ Dowsett M. Clinical utility of the IHC4+C score in oestrogen receptor-positive early breast cancer: a prospective decision impact study. $\mathrm{Br}$ J Cancer. 2015;113(3):390-395.

4. Wang $M$, Chen $H$, Wu $K$, Ding $A$, Zhang $M$, Zhang P. Evaluation of the prognostic stage in the 8th edition of the American Joint Committee on Cancer in locally advanced breast cancer: An analysis based on SEER 18 database. Breast Edinb Scotl. 2018;37:56-63.

5. Abubakar $M$, Figueroa J, Ali $H R$, et al. Combined quantitative measures of ER, PR, HER2, and KI67 provide more prognostic information than categorical combinations in luminal breast cancer. Mod Pathol. 2019;32(9):1244-1256. doi: 10.1038/s41379-019-0270-4.

6. Bakre MM, Ramkumar C, Attuluri AK, et al. Clinical validation of an immunohistochemistrybased CanAssist-Breast test for distant recurrence prediction in hormone receptor-positive breast cancer patients. Cancer Med. 2019;8(4):17551764. doi:10.1002/cam4.2049.

7. Gnant M, Filipits $\mathbf{M}$, Greil $\mathbf{R}$, et al. Predicting distant recurrence in receptor-positive breast cancer patients with limited clinicopathological risk: using the PAM50 Risk of Recurrence score in 1478 postmenopausal patients of the ABCSG- 8 trial treated with adjuvant endocrine therapy alone. Ann Oncol Off J Eur Soc Med Oncol. 2014;25(2):339-345.

8. Prakash C, Gunda A, Attuluri AK, et al. Risk stratification in early-stage estrogen receptor+/HER2-breast cancer patients: Comparative analysis of cost-effective methods. $]$ Curr Oncol. 2018;1(1):5. 